\title{
PRÓ-FÁRMACO ATIVADO POR ENZIMA, UMA ESTRATÉGIA PROMISSORA NA QUIMIOTERAPIA
}

\author{
Lorena Blau, Renato Farina Menegon e Man Chin Chung*
}

Departamento de Fármacos e Medicamentos, Faculdade de Ciências Farmacêuticas, Universidade Estadual Paulista "Júlio de Mesquita Filho", CP 502, 14801-902 Araraquara - SP, Brasil

Recebido em 9/6/05; aceito em 6/12/05; publicado na web em 1/8/06

\begin{abstract}
PRODRUG ACTIVATION BY ENZYME, A PROMISING STRATEGY FOR CHEMOTHERAPY. Strategies that promote selective activation of prodrugs by enzymes can be divided into two major classes: 1) deliver of a monoclonal antibody-enzyme immunoconjugate that can recognize a specific antigen and promote the prodrug to a citotoxic drug, with a high selectivity for the target cells, and 2) selective gene delivery encoding an enzyme that can promote the prodrug to a citotoxic drug for the target cells. In this article are discussed ADEPT (antibody-directed enzyme prodrug therapy), GDEPT (gene-directed enzyme prodrug therapy), VDEPT (virus-directed enzyme prodrug therapy), GPAT (genetic prodrug activation therapy) and PDEPT (polymer-directed enzyme prodrug therapy) approaches, their clinical trials, advantages, disadvantages and perspectives.
\end{abstract}

Keywords: prodrugs; enzymes; cancer.

\section{INTRODUÇÃO}

Novas estratégias que visam solucionar problemas da quimioterapia, principalmente a antineoplásica, como a baixa concentração de antineoplásicos em tumores, toxicidade sistêmica ${ }^{1-4}$, ausência de seletividade entre células tumorais e normais e o aparecimento de células tumorais resistentes aos quimioterápicos ${ }^{5,6}$, vêm sendo estu$\operatorname{dadas}^{7,8}$. Este artigo trata de estratégias que utilizam enzimas ativadoras de pró-fármacos.

Pró-fármaco pode ser definido como forma de transporte inativo que in vivo, mediante reação química ou enzimática, libera o princípio ativo no local de ação ou próximo dele, sendo obtido através de processo de modificação molecular denominado latenciação ${ }^{9}$. Mediante a escolha de transportadores apropriados é possível a seletividade de ação do princípio ativo desejado ${ }^{10}$.

Baseado neste princípio, foram desenvolvidos os sistemas ADEPT ("antibody-directed enzyme-prodrug therapy"), PDEPT ("polymer-directed enzyme-prodrug therapy"), GDEPT ("genedirected enzyme-prodrug therapy"), VDEPT ("virus-directed enzyme-prodrug therapy") e GPAT ("genetic prodrug activation therapy"). Nestes sistemas, são necessárias duas etapas, a primeira onde a enzima ativadora de pró-fármaco é administrada e direcionada seletivamente às células alvo, como por ex., em células tumorais (método que varia em cada sistema utilizado). A segunda etapa consiste na administração sistêmica do pró-fármaco, que será convertido pela ação da enzima ativadora, que já se encontra na célula alvo, em altas concentrações de fármaco ativo ${ }^{11,12}$.

Atualmente, as estratégias utilizando enzimas ativadoras de prófármacos são divididas em duas classes: ação de enzima ativa na superfície dos tecidos alvo, mediada por um anticorpo monoclonal (ADEPT) ou por polímero (PDEPT) e, ação de um gene que codifica a transcrição de uma enzima dentro de células alvo (GDEPT/VDEPT/GPAT) ${ }^{13}$.

A vantagem destas estratégias é que a enzima pode converter inúmeras moléculas de pró-fármaco em moléculas de fármaco ativo, pois uma enzima pode catalisar a reação de 1000 moléculas de pró-

*e-mail: chungmc@fcfar.unesp.br fármaco em fármaco ativo por $\min ^{14}$, aumentando a concentração de fármaco ativo em células alvo.

Para que estas estratégias terapêuticas sejam bem sucedidas, é necessário que enzimas e pró-fármacos possuam certas características. A enzima ideal deve ser facilmente acessível e converter o pró-fármaco em fármaco ativo com uma alta atividade catalítica a $37^{\circ} \mathrm{C}$, em $\mathrm{pH}$ próximo ao neutro ${ }^{15}$, por uma reação não reversível e deve possuir expressão suficiente nas células alvo. A enzima ou uma homóloga dela não deve estar presente em tecidos humanos ou, se estiver, deve ser expressa somente em baixas concentrações nos demais tecidos ${ }^{16,17}$. Se a enzima estiver presente em altas concentrações em tecidos humanos, poderá promover a ativação do pró-fármaco em outros tecidos, causando intensa toxicidade. Por outro lado, se uma enzima não humana for utilizada, pode ocorrer o risco de reações de hipersensibilidade induzida por intensa resposta imune e conseqüente falha na terapia, depois de poucos ciclos (considera-se 1 ciclo a realização de todas as etapas).

A escolha da enzima é um fator importante, pois o requerimento de um cofator pode ser uma desvantagem (no caso de ADEPT), uma vez que a presença deste cofator pode ser um passo limitante no processo de liberação do agente citotóxico ${ }^{18}$.

É necessário que o pró-fármaco seja um bom substrato para a enzima que se expressa nas células alvo, mas que não possa ser ativado por enzimas endógenas de outros tecidos. Deve possuir o maior diferencial possível de citotoxicidade entre o pró-fármaco e seu respectivo fármaco ativo. É desejável que o fármaco ativo seja altamente difundível por células adjacentes que não expressam a enzima, ou seja, deve possuir a capacidade de destruir células vizinhas não expressantes ${ }^{15}$. Em adição, a meia-vida do fármaco ativo deve ser longa o suficiente para induzir a morte em células vizinhas não expressantes, no entanto, deve ser curta o suficiente para evitar que o fármaco ativo penetre na corrente sangüínea ${ }^{15}$.

\section{ADEPT - "ANTIBODY-DIRECTED ENZYME-PRODRUG THERAPY"}

O sistema ADEPT é uma estratégia de dois passos, na qual o $1^{\circ}$ consiste na administração de anticorpo monoclonal (com afinida- 
de para antígenos específicos de células alvo) conjugado com uma enzima que tem a função de converter um pró-fármaco inativo em fármaco ativo.

O $2^{\circ}$ passo consiste na administração de um pró-fármaco que contém um substrato da enzima ligado covalentemente a sua estrutura. A enzima promoverá a catálise da reação de liberação do fármaco ativo, seletivamente, na célula alvo.

Os primeiros sistemas utilizando anticorpos eram constituídos de conjugados para terapia em uma única etapa, acoplando-se um anticorpo diretamente ao fármaco. Este método não se mostrou eficaz, devido ao número limitado de moléculas de fármaco que poderiam ser acopladas ao anticorpo e aos problemas de atividade, pois nem sempre ocorria a liberação do fármaco ativo na célula alvo ${ }^{19,20}$. Além disso, havia limitações práticas na dosagem adequada aos pacientes no caso de moléculas de grande massa molecular.

A maior vantagem do sistema ADEPT, que consiste em anticorpo monoclonal acoplado à enzima capaz de converter pró-fármacos em fármacos, em relação ao sistema de anticorpo ligado diretamente a fármacos, é que neste último apenas um número limitado de moléculas que estão acopladas ao anticorpo pode chegar ao alvo, enquanto que no ADEPT a enzima acoplada ao anticorpo monoclonal (mAc) pode converter inúmeros pró-fármacos em fármacos ativos. Um conjugado mAc-enzima catalisa a reação de 1000 moléculas de prófármaco em moléculas de fármaco ativo por $\min ^{14}$ (Figura 1).

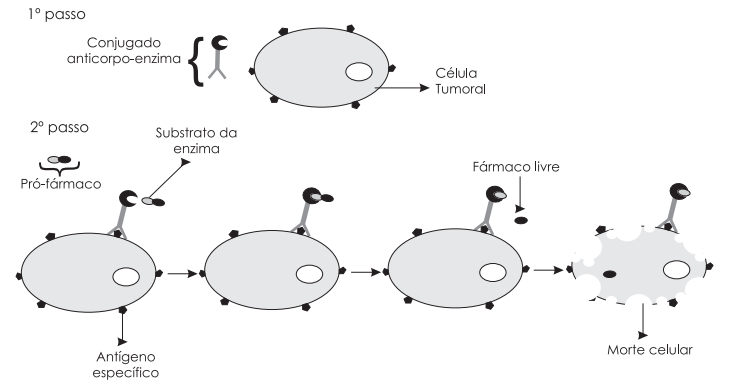

Figura 1. Sistema ADEPT

É necessário um intervalo de tempo entre os passos, pois os conjugados anticorpo-enzima, que não se ligaram às células alvo, devem ser eliminados da corrente sangüínea antes da administração do pró-fármaco. De outra forma, uma ativação indesejável do pró-fármaco poderá ocorrer em lugares remotos, ao invés de ocorrer exclusivamente nas células alvo.

Esta eliminação pode demorar dias, e o risco de reações imunogênicas é aumentado com o tempo de exposição. Este fator pode limitar a terapia utilizando o sistema ADEPT para poucos ciclos (cada administração das duas etapas $=1$ ciclo). Na quimioterapia antineoplásica, devido à baixa vascularização em tumores, o emprego de poucos ciclos limita a ação do imunoconjugado, não sendo possível a distribuição para todas as células tumorais, diminuindo a eficácia deste sistema ${ }^{21,22}$.

Para resolver esses problemas, muitas propostas têm sido apresentadas a fim de acelerar a depuração do conjugado.

Um dos instrumentos mais comumente usados para encurtar o tempo de espera para administração do pró-fármaco é a utilização de um $2^{\circ}$ anticorpo, que possui maior afinidade com o sítio ativo da enzima, inativando o conjugado que ainda permanece na circulação.

A galactonização de um $2^{\circ}$ anticorpo que se liga ao imunoconjugado anticorpo-enzima proporciona aumento na absorção pelo fígado, mediante a ligação a receptores de galactose presentes neste órgão ${ }^{18,23}$. Podese também utilizar fragmentos de anticorpos conjugados à enzima, que são mais facilmente depurados que anticorpos inteiros ${ }^{24}$.
Adicionalmente a um conjugado anticorpo-enzima, o uso de agentes como o 5,6-dimetilxantenona-4-ácido acético diminui seletivamente o fluxo sangüíneo, causando extensa necrose, e aumenta a concentração do conjugado anticorpo-enzima retido no tumor, potencializando significativamente a inibição do crescimento da célula neoplásica, em relação à utilização do sistema ADEPT isoladamente ${ }^{25}$.

Para minimizar a imunogenicidade induzida pelo sistema ADEPT, duas estratégias podem ser utilizadas. A primeira consiste na utilização de formas mutantes de enzimas humanas, as quais podem proporcionar menor toxicidade sistêmica que enzimas endógenas e menor imunogenicidade que as não humanas ${ }^{26}$. Uma forma de enzima humana mutante de CPA1 (carboxipeptidase A1) conjugada a um anticorpo com afinidade para células tumorais foi capaz de ativar um pró-fármaco de metotrexato; felizmente este prófármaco não foi um bom substrato para a enzima endógena CPA $1^{26}$. A outra estratégia consiste no uso de tecnologia DNA recombinante, combinando regiões variáveis VL e VH de anticorpos não humanos, responsáveis pelo reconhecimento do antígeno alvo, com regiões constantes de anticorpos humanos (Figura 2) ) $^{24,27}$.

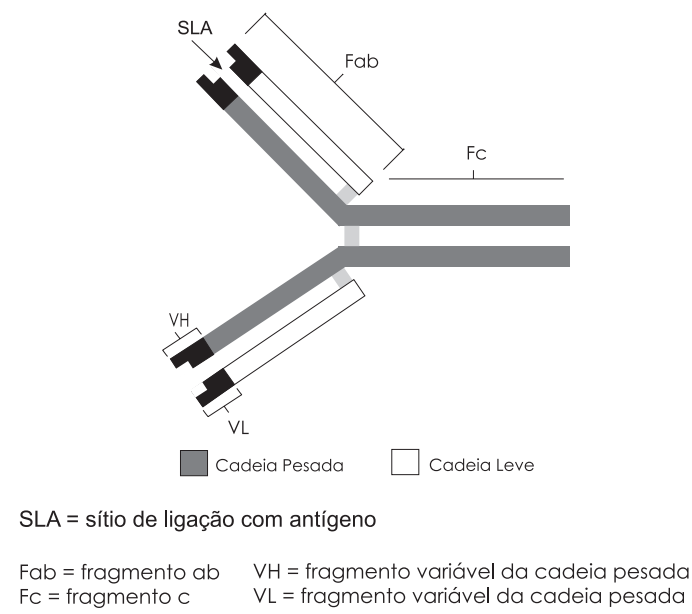

Figura 2. Representação do anticorpo IgG e suas regiões

\section{Conjugado anticorpo-enzima}

A ligação de um anticorpo com uma enzima pode ser realizada quimicamente ${ }^{28,29}$ ou através de outros meios. Para a formação de ligação química, reagentes bifuncionais são usados para unir dois peptídeos. Usualmente, um grupo acilante é usado para modificar a cadeia lateral de lisinas em uma $1^{\text {a }}$ proteína (anticorpo ou enzima) e uma ligação envolvendo um grupo tiol providencia a ligação da $2^{\mathrm{a}}$ proteína (anticorpo ou enzima) com a $1^{\text {a }}$. Maleimidas, que podem sofrer adição de Michael resultando em tioéteres, podem ser utilizadas para a ligação com a $2^{\mathrm{a}}$ proteína $^{30}$ (Figura 3 ).

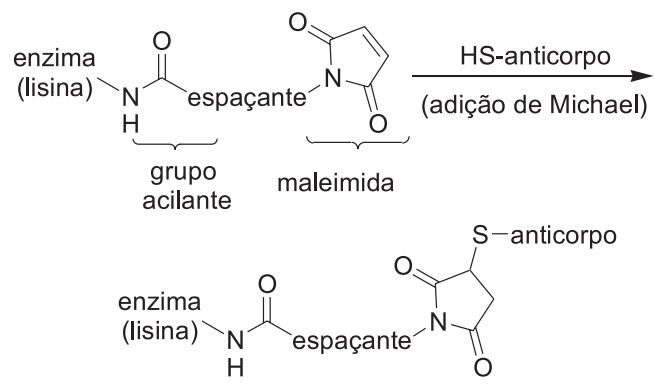

Figura 3. Utilização de maleimida para a ligação química entre anticorpo $e$ enzima 
Outras possibilidades de ligação envolvem anticorpos biespecíficos ou bifuncionais, que possuem tanto sítios de ligação para o antígeno alvo quanto sítios de reconhecimento para a enzima ${ }^{31}$. Recentemente, utiliza-se da tecnologia de DNA recombinante, promovendo fusão de proteínas $^{32-35}$. A conjugação da enzima não deve limitar o funcionamento do sistema ADEPT ${ }^{17}$.

\section{Enzimas empregadas no sistema ADEPT}

\section{$\beta$-glicuronidase}

A $\beta$-glicuronidase utilizada por um sistema ADEPT pode ser uma enzima humana presente intracelularmente em lisossomas, ou uma enzima de origem bacteriana derivada da Escherichia coli. É uma enzima que catalisa a clivagem da ligação glicosídica em análogos de ácido glicurônico ${ }^{36}$.

A enzima humana é uma ótima candidata para ativação seletiva de pró-fármacos, pois apresenta menor risco de imunogenicidade. Tem sido observada atividade enzimática de $\beta$-glicuronidase em altos níveis, extracelularmente, em tecidos tumorais necróticos, o que faz com que a enzima humana apresente vantagens para sistemas ADEPT. Muitos pró-fármacos glicuronizados têm sido sintetizados para serem ativados por esta enzima ${ }^{36}$ (Figura 4 )

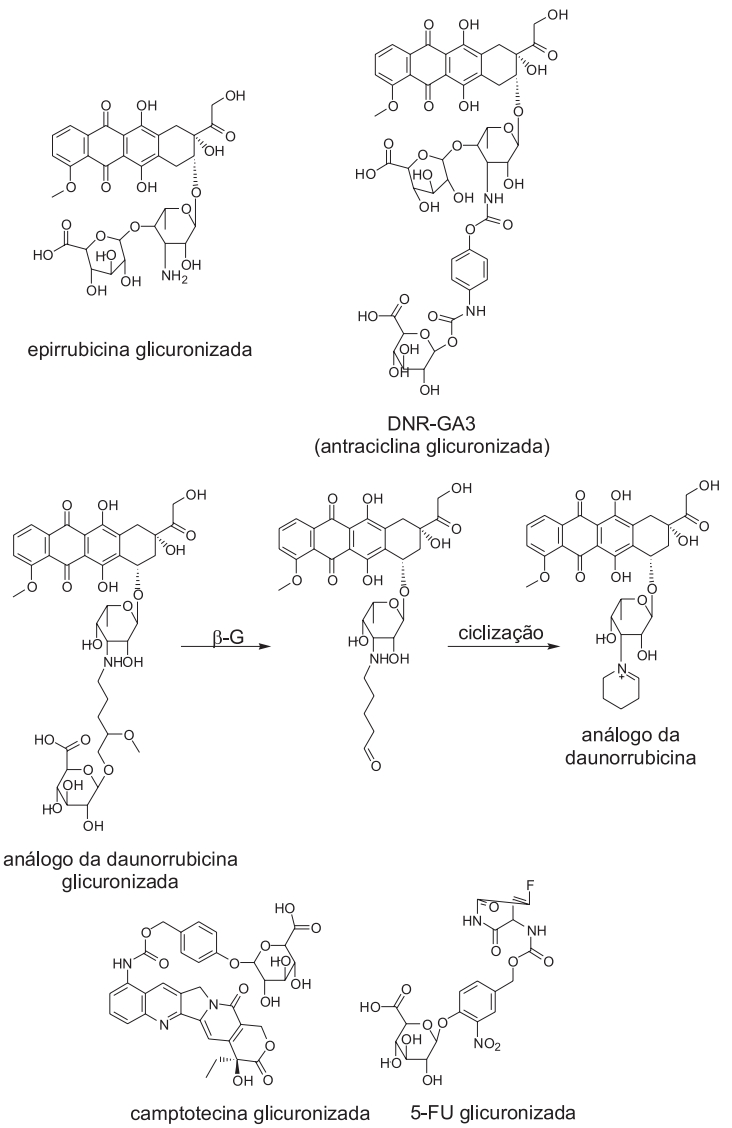

Figura 4. Pró-fármacos glicuronizados e ativação do análogo da daunorrubicina glicuronizada pela $\beta-G$

Eles são relativamente pouco tóxicos, devido à sua natural hidrofilicidade, o que previne que estes pró-fármacos penetrem dentro das células e entrem em contato com $\beta$-glicuronidase lisossômica. O principal problema do uso clínico dos pró-fármacos glicuronizados é a rápida eliminação renal, por isso, o planejamento de pró-fármacos menos hidrofílicos para uma eliminação renal mais lenta se faz necessário, o que adicionalmente pode resultar em maior tempo de exposição dos pró-fármacos nos tumores.
Wang et al. ${ }^{37,38}$ planejaram sistemas ADEPT, os quais utilizam $\beta$-glicuronidase derivada de Escherichia coli. Foi sintetizado um pró-fármaco glicuronizado derivado de mostarda nitrogenada (Figura 5) cerca de 150 vezes menos citotóxico quando comparado com o fármaco ativo, contra células COLO 205 de câncer de cólon. Quando o pró-fármaco foi administrado juntamente com o imunoconjugado anticorpo- $\beta$-glicuronidase $(\mathrm{mAc}-\beta \mathrm{G})$, a citotoxicidade foi similar à do fármaco livre.

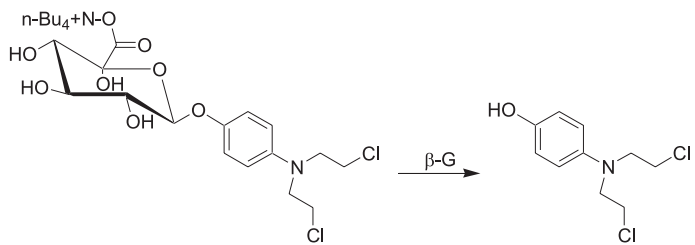

Figura 5. Conversão do pró-fármaco glicuronizado em fármaco livre pela $\beta$ - $G$

Um pró-fármaco glicuronizado do análogo da daunorrubicina foi sintetizado por Bakina e colaboradores ${ }^{39}$ utilizando um tipo diferente de espaçante. Após a hidrólise da porção glicurônica, o aldeído formado reage com o grupo amino do açúcar da daunorrubicina. A ciclização do agente espaçante resulta na geração do análogo altamente tóxico da daunorrubicina (Figura 4).

Para o sistema ADEPT, que utiliza $\beta$-glicuronidase, desenvolveram-se previamente conjugados quimicamente acoplados a anticorpos $^{40,41}$.

A maior desvantagem destes conjugados é devido à ligação química propiciar uma perda de especificidade da enzima ou do anticorpo, resultando freqüentemente em redução da atividade enzimática ou da capacidade ligante do anticorpo do imunoconjugado. Como alternativa, a tecnologia de DNA recombinante pode ser usada para preparação de proteínas fundidas. Estas proteínas podem ser vantajosas para administrações repetitivas, evitando um aumento da resposta imune (Figura 6).

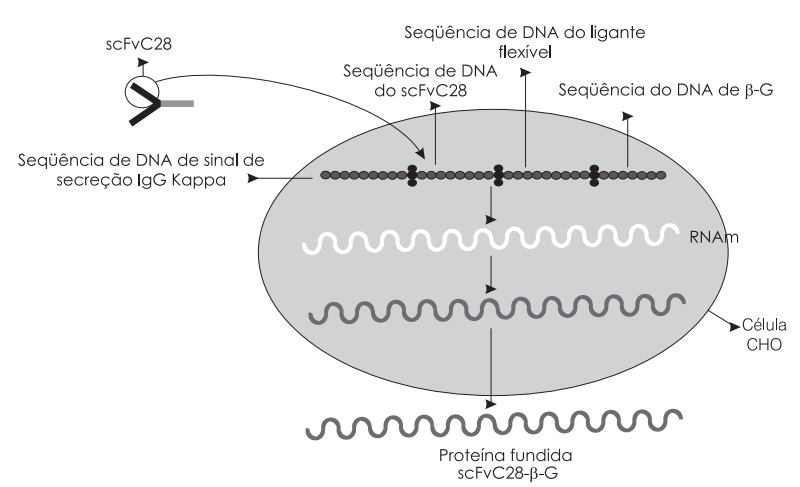

Figura 6. Uso da tecnologia de DNA recombinante para construção da proteína fundida $s c F v C 28-\beta-G$

De Graff e colaboradores ${ }^{42}$ construíram uma proteína fundida, constituída de uma seqüência que codifica um fragmento variável de cadeia simples do anticorpo humano $\mathrm{C} 28$ ( $\mathrm{scFvC} 28)$, que se liga às células epiteliais, e de uma seqüência que codifica a enzima $\beta$ glicuronidase humana ( $\mathrm{scFvC} 28-\beta-\mathrm{G})$. As seqüências que codificam scFvC28 e a enzima humana foram unidas por uma seqüencia que codifica um ligante flexível e foram precedidas por uma sequiência que codifica o sinal de IgG Kappa, responsável pela secreção da proteína fundida. Uma linhagem de células $\mathrm{CHO}$ foi construída para secretar a proteína fundida scFvC28- $\beta-\mathrm{G}$. 
A proteína fundida secretada pelas células $\mathrm{CHO}$, depois de isolada, foi capaz de converter o pró-fármaco não tóxico de doxorrubicina em fármaco ativo. Verificou-se a presença do fármaco ativo em todas as células, in vitro, quando ao menos $10 \%$ das células expressavam a proteína fundida. Esta é a primeira proteína fundida, completamente humana e funcional, para uso futuro em pró-fármacos glucuronizados não tóxicos, de ativação específica em tumores ${ }^{42}$.

\section{Peptidases}

\section{Carboxipeptidase G2 (CPG2)}

É uma metaloenzima de Pseudomonas sp., cuja função normal é catalisar a conversão de folato reduzido e não reduzido em ácido pteróico e ácido L-glutâmico ${ }^{14}$ (Figura 7).

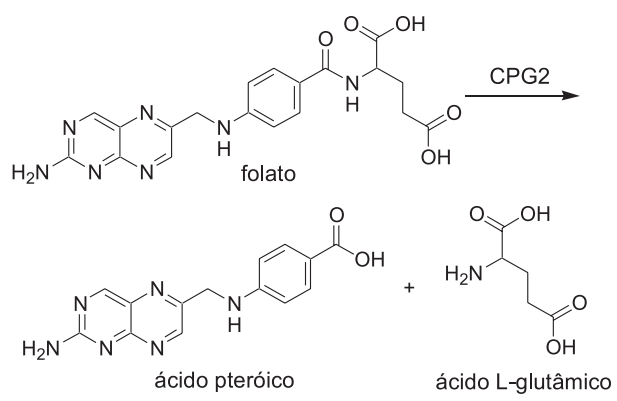

Figura 7. Conversão de folato em ácido pteróico e ácido L-glutâmico pela $C P G 2$

Bagshawe e Springer desenvolveram três pró-fármacos de agentes alquilantes de mostardas nitrogenadas (1, 2 e $\mathbf{3})$, para uso em $\mathrm{ADEPT}^{16,43-45}$. Os fármacos $\mathbf{4}, \mathbf{5}$ e $\mathbf{6}$ foram transformados nos prófármacos 1, 2 e 3 através de uma ligação amídica com o substrato da enzima, o ácido glutâmico. Na presença do conjugado mAc-CPG2, a ligação amídica é clivada, liberando os fármacos livres $(4,5$ e 6$)$ e ácido glutâmico (Figura 8).

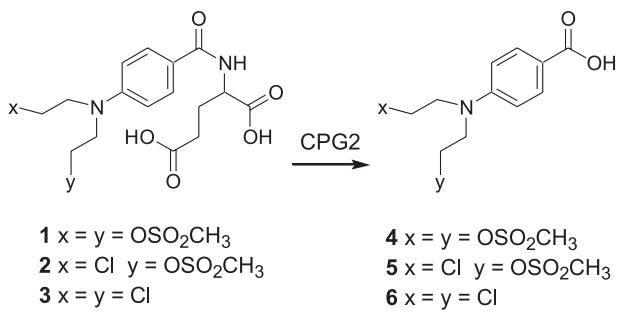

Figura 8. Conversão de 1, 2 e 3 pela enzima CPG2 em seus respectivos fármacos livres 4,5 e 6

Os três pró-fármacos 1, 2 e $\mathbf{3}$ foram relativamente não tóxicos quando comparados as seus respectivos fármacos livres 4,5 e $\mathbf{6}^{16,43}$.

A atividade antitumoral deste sistema ADEPT carboxipeptidase/ mostarda nitrogenada tem sido demonstrada in vitro ${ }^{16} \mathrm{e}$, também, em modelo xenográfico utilizando ratos e regressões de tumor de cólon humano LS174T têm sido observadas ${ }^{44,45}$.

Estes pró-fármacos antineoplásicos sintetizados não foram totalmente destituídos de ação alquilante (forma de transporte inativo). Entretanto, o pró-fármaco 2 apresentou atividade alquilante 17 vezes menor que o fármaco de origem $\mathbf{5}$, contra 2 e 3,6 vezes a dos pró-fármacos 4 e $\mathbf{6}$. Estes dados sugerem que o pró-fármaco 2 apresenta menor índice de toxicidade, sendo bastante interessante na utilização do sistema ADEPT, pois terá atividade somente após a clivagem em fármaco ativo na célula tumoral.

A combinação de um imunoconjugado mAc-CPG2 e pró-fármaco 2, é apenas um dos sistemas ADEPT que estão em fase de pesquisa clínica ${ }^{46,47}$. A pesquisa clínica, neste caso, também incorpora um passo adicional, a utilização de um anticorpo SB 43 galactosilado, que rapidamente elimina o imunoconjugado mAc-CPG2 da circulação.

Em humanos, são necessários 7 dias para uma adequada depuração do conjugado mAc-CPG2 do plasma para que o pró-fármaco 2 possa ser administrado seguramente, evitando sua ativação no plasma e uma toxicidade sistêmica ${ }^{16}$.

Com a utilização de um $2^{\circ}$ anticorpo galactosilado para depuração deste imunoconjugado, verificou-se que em 10 pacientes com carcinoma colorretal, a atividade da enzima CPG2 foi encontrada apenas em biópsias de tumores metastáticos, mas não foi encontrada em células normais, depois da introdução do anticorpo depurante. A rápida liberação do fármaco ativo, com meia vida de $36 \pm 14$ min no plasma, foi observada neste sistema ${ }^{22}$.

Todos os pacientes desenvolveram anticorpos humanos contra anticorpos de rato (HAMA) e anticorpos contra a CPG2. Anticorpos anti-CPG2 séricos de um paciente foram capazes de inibir a atividade da CPG2 in vitro, o que pode limitar ciclos repetitivos neste sistema $\mathrm{ADEPT}^{48}$. Para diminuir esta formação de anticorpos antiCPG2, foi desenvolvida uma proteína mutante de fusão recombinante, de um fragmento de cadeia simples variável do anticorpo contra antígeno o carcinoma embriogênico com uma proteína mutante de CPG2, e houve uma significativa redução na formação de anticorpos anti-CPG2, verificada no plasma de 11 pacientes após a terapia, o que induziu a formação de antianticorpos ${ }^{49}$. O sucesso desta modificação foi também demonstrado em humanos tratados com esta proteína mutante, confirmando os ensaios anteriores ${ }^{50}$. Estes resultados sugerem que o sistema ADEPT, baseado em CPG2, é uma promissora terapia antineoplásica.

\section{$\beta$-Lactamase}

As $\beta$-lactamases, de origem não mamífera, estão disponíveis comercialmente em sua forma purificada. São altamente seletivas para substratos que contêm anel $\beta$-lactâmico sendo, produzidas por bactérias com a função de inativar antibióticos com anel $\beta$-lactâmico, e possuem toxicidade mínima em mamíferos.

A utilização de cefalosporinas como substratos para enzima $\beta$ lactamase permite um acoplamento covalente de uma variedade de agentes antineoplásicos a sua estrutura; a liberação do fármaco ativo ocorre eficientemente após a catálise enzimática (Figura 9). Excelentes resultados usando o conjugado mAc- $\beta$-lactamase e cefalosporinas, como substratos para esta enzima, têm sido obtidos in vivo ${ }^{14}$.

Em 1990, a Empresa Farmacêutica Eli Lilly \& Co. patenteou o sistema ADEPT utilizando o antineoplásico metotrexato (MTX) ${ }^{51}$. Quando uma solução do pró-fármaco 7 foi tratada com $\beta$-lactamase, o MTX foi rapidamente liberado (Figura 10), sugerindo que o pró-

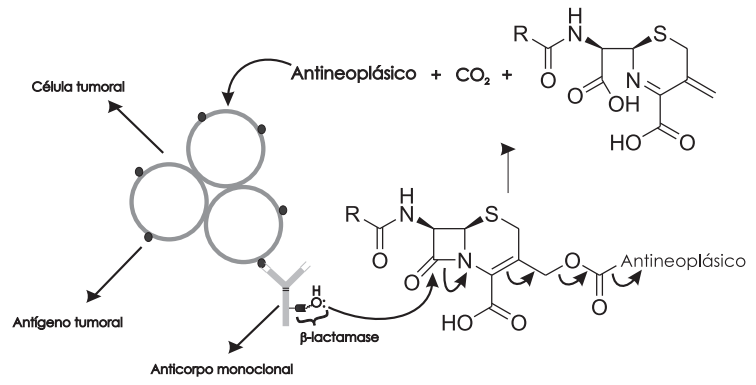

Figura 9. Representação do sistema ADEPT na terapia antineoplásica utilizando cefalosporina como substrato para enzima $\beta$-lactamase 
fármaco 7 é um bom substrato para a enzima. Infelizmente, a citotoxicidade de 7 sem a adição da enzima $\beta$-lactamase não foi diferente do MTX, o que demonstra uma hidrólise inespecífica do éster, ou seja, uma hidrólise promovida por esterases sangüíneas, antes de atingir o alvo (células tumorais).

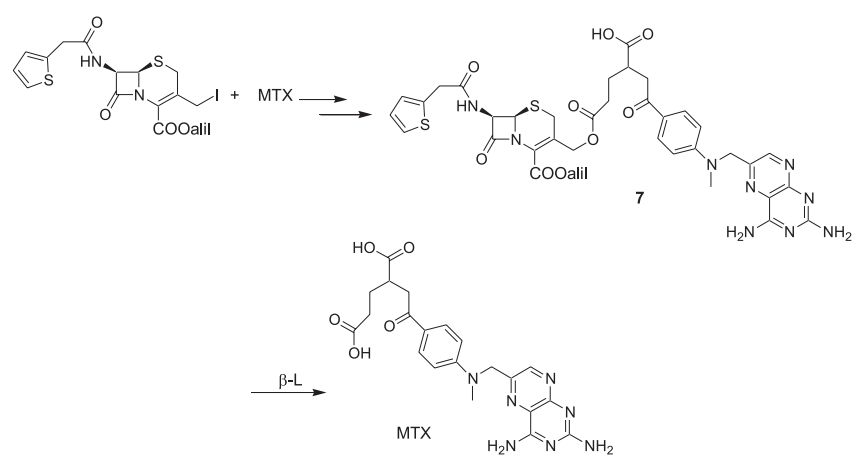

Figura 10. Conversão do pró-fármaco 7 em metotrexato (MTX) pela $\beta$ lactamase $(\beta-L)$

Em outro trabalho ${ }^{52}$, utilizou-se o mesmo transportador cefalosporínico e hidrazida de desacetilvimblastina (8) para obtenção do pró-fármaco 9 (Figura 11). Quando o pró-fármaco 9 foi submetido à hidrólise pela $\beta$-lactamase, o anel $\beta$-lactâmico foi rapidamente hidrolisado, entretanto, a liberação do fármaco $\mathbf{8}$ foi demasiadamente lenta. Foram propostas, então, modificações na síntese do pró-fármaco.
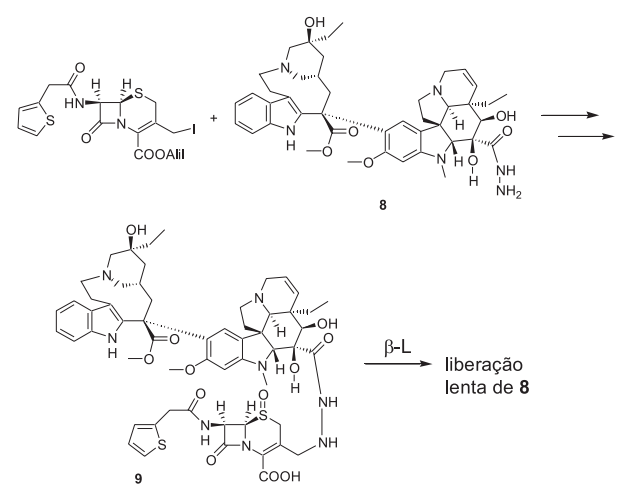

Figura 11. Conversão do pró-fármaco 9 em hidrazida de desacetilvimblastina (8) pela $\beta$ - $L$

O pró-fármaco $\mathbf{1 0}$ (Figura 12) foi um excelente substrato para o conjugado mAc- $\beta$-lactamase e, diferentemente, do pró-fármaco $\mathbf{9}$, a liberação do fármaco $\mathbf{8}$ foi adequada e observada por HPLC ${ }^{53}$. A diferença entre os pró-fármacos $\mathbf{9}$ e $\mathbf{1 0}$ encontra-se na ligação da cefalosporina com o fármaco. O diferencial, in vitro, de citotoxicidade entre o pró-fármaco 10 e o fármaco 8 em células LS174T tumorais do colorretal humano foi 5 vezes menor (em base molar) entre o prófármaco e o fármaco ativo, e para períodos curtos de incubação, observou-se toxicidade ainda menor. Estudos in vivo, utilizando ratos, empregando mAc- $\beta$-lactamase e o pró-fármaco 10, demonstraram que este sistema ADEPT proporcionou uma redução nos tumores e que também foi significativamente mais ativo que o pró-fármaco $\mathbf{1 0}$ e o fármaco 8 , quando administrados isoladamente ${ }^{54}$.

Veinberg ${ }^{55}$ e Jungheim ${ }^{14}$ desenvolveram sistemas ADEPT utilizando a doxorrubicina (Figura 13) como agente antineoplásico. O pró-fármaco $\mathbf{1 1}$ foi um bom substrato para $\beta$-lactamase, sendo a doxorrubicina rapidamente liberada na presença da enzima. Como
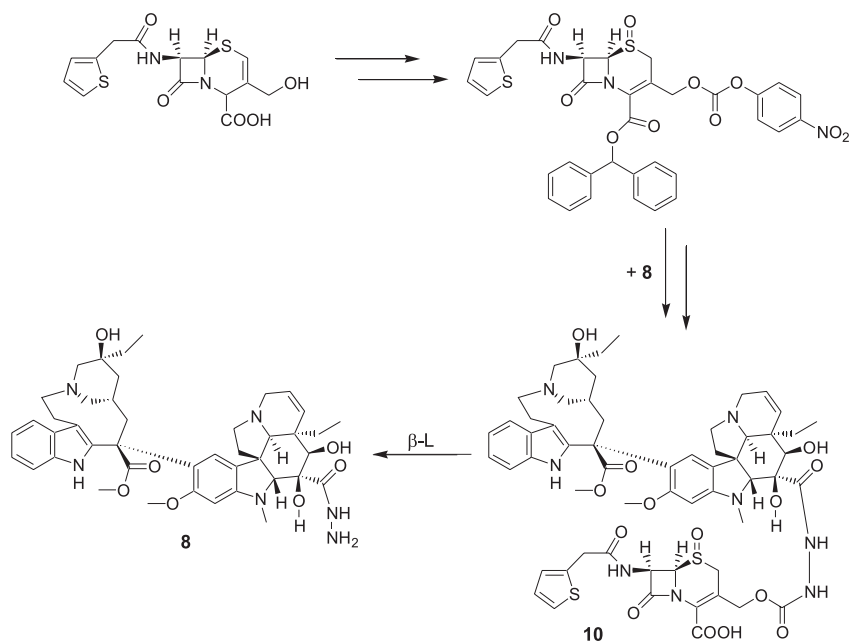

Figura 12. Conversão do pró-fármaco 10 em hidrazida de desacetilvimblastina $(8)$ pela $\beta$ - $L$
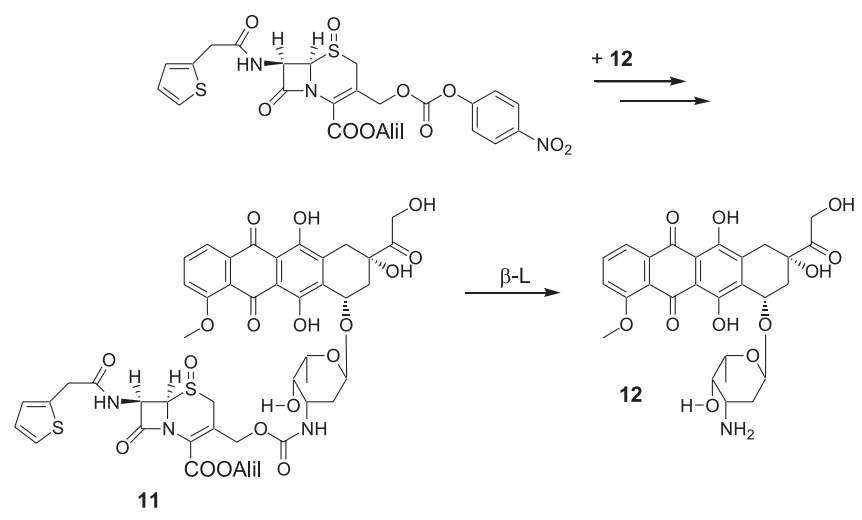

Figura 13. Conversão do pró-fármaco 11 em doxorrubicina (12) $\beta-L$

esperado, o pró-fármaco $\mathbf{1 1}$ foi menos citotóxico que a doxorrubicina (12) contra células LS174T de câncer colorretal humano. A associação do imunoconjugado mAc- $\beta$-lactamase e o prófármaco 11 resultou em uma atividade citotóxica equivalente à da doxorrubicina, in vitro.

Experimentos in vivo demonstraram que este sistema ADEPT foi capaz de suprimir tumor de cólon LS174T e tumor de ovário humano OVCAR-3, em modelos xenográficos ${ }^{14}$.

Nos antigos sistemas ADEPT utilizava-se $\beta$-lactamase ligada quimicamente a um fragmento variável de um anticorpo monoclonal. Atualmente, utiliza-se um fragmento variável de cadeia simples de um anticorpo monoclonal ligado à $\beta$-lactamase. A ligação é realizada por meio da tecnologia de fusão de proteínas DNA recombinante, a fim de minimizar a formação de anticorpos contra os anticorpos empregados nesta terapia e facilitar a difusão deste imunoconjugado, desenvolvido a partir de fragmentos menores. Testes in vitro destes novos sistemas ADEPT demonstraram a ativação de cefalosporina derivada de paclitaxel em fármaco ati$\mathrm{vo}^{56}$, assim como em uma cefalosporina derivada de ácido monoidroguaiarético, que demonstrou atividade contra leucemia humana (K562), carcinoma de mama (MCF7), câncer de pulmão (A549), câncer de cólon (COLO 205) e câncer de pâncreas (Capan 2 e $\mathrm{MiaPaCa} 2)^{57}$. Duas novas séries de cefalosporinas derivadas de ácido retinóico, também com o uso da tecnologia de fusão de proteínas, apresentaram atividade anticancerígena ${ }^{58}$ (Figura 14).

Com o objetivo de aumentar o rendimento e a estabilidade, utilizando esta mesma tecnologia, foi desenvolvida através de muta- 


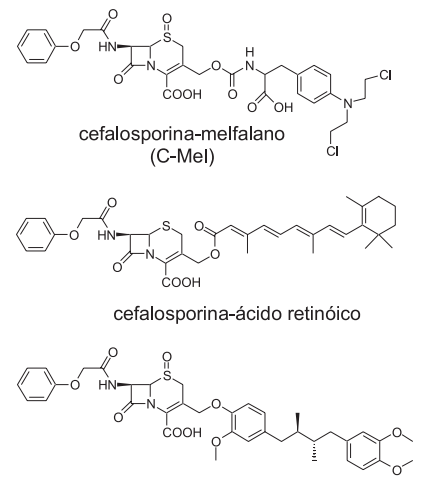

cefalosporina-ácido monoidroguaiarético

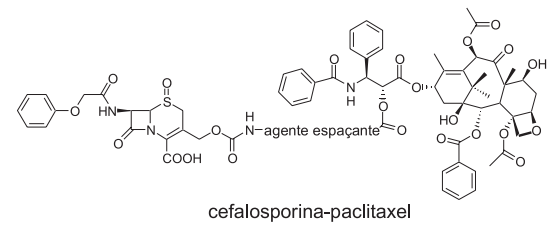

Figura 14. Pró-fármacos derivados de cefalosporina

ções a proteína L49-sFv-bL, constituída de uma cadeia simples de fragmento variável L49 fundido à $\beta$-lactamase, que demonstrou, em testes in vitro e in vivo, usando modelos xenográficos, atividade antitumoral quando associada ao pró-fármaco cefalosporinamelfalano $(\mathrm{C}-\mathrm{Mel})^{59}$.

Recentemente, foram desenvolvidos sistemas ADEPT que utilizam fragmentos menores de anticorpos que possuem um único domínio inteiramente funcional e desprovidos de cadeia leve. São muito estáveis, possuindo sítios de ligação com antígeno diferente dos anticorpos convencionais, sendo altamente solúveis e difusíveis. Estes sistemas vêm sendo utilizados por Cortez-Retamozo et al. ${ }^{60} \mathrm{e}$ Stijilemans et al. ${ }^{61}$ para tratamento de câncer e da doença do sono causada pelo agente etiológico Trypanosoma brucei, respectivamente.

\section{Citosina deaminase}

Citosina deaminase (CD) é uma enzima capaz de converter a citosina em uracila. Senter e colaboradores ${ }^{62}$ têm relatado as vantagens desta atividade catalítica na utilização de CD para converter o agente antifúngico flucitosina (5-FC) no agente tumoral fluoruracila (5-FU) (Figura 15).

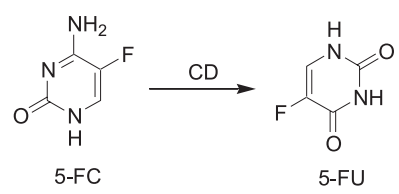

Figura 15. Conversão do pró-fármaco flucitosina $(5-F C)$ em fluoruracila (5-FU) pela $C D$

A citotoxicidade do pró-fármaco 5-FC foi cerca de 10000 vezes menor em células de adenocarcinoma pulmonar H2891 que com o fármaco 5-FU. Quando foi introduzido o imunoconjugado mAc-CD às células H2891, seguido da posterior administração do pró-fármaco 5FC, a atividade antitumoral observada foi igual à do fármaco 5-FU. Apesar de experimentos in vitro apresentarem resultados promissores, este sistema está restrito à utilização de um único fármaco, a fluoruracila.

Devido à pobre difusão e estabilidade de conjugados anticorpoenzima baseados em IgG, a tecnologia de fusão de proteínas DNA recombinante tem sido empregada para solucionar esses problemas. Experimentos in vitro demonstraram um aumento da ativida- de antitumoral do 5-FC em células antígeno-positivas em 300 vezes, em um sistema ADEPT que utiliza esta tecnologia de fusão de uma cadeia simples de fragmento de anticorpo A33, que se liga a tumores, com a enzima $\mathrm{CD}$, usando 5-FC como pró-fármaco, demonstrando o grande potencial desta estratégia ${ }^{63}$.

\section{PDEPT - "POLYMER-DIRECTED ENZYME-PRODRUG THERAPY"}

PDEPT $^{64}$ é um novo sistema que vem sendo empregado para antineoplásicos, realizado também em duas etapas. A diferença deste para o ADEPT é a utilização de um pró-fármaco polimérico e um conjugado polímero-enzima para gerar, rapida e especificamente, um fármaco citotóxico em tumores.

A estrutura anatômica dos vasos tumorais desempenha um papel importante na distribuição do fármaco no espaço intertiscial; estes apresentam aumento da permeabilidade microvascular em relação ao vaso normal, permitindo a penetração de macromoléculas como a $\mathrm{N}$ (2-hidroxipropil)-metacrilamida (HPMA). Além disso, os tecidos tumorais são caracterizados também por alta pressão intertiscial, que pode retardar o extravasamento de macromoléculas; a falta de sistema linfático para drenagem resulta em acúmulo de macromoléculas no interior dos tecidos tumorais, ocasionando o efeito denominado EPR (aumento da permeabilidade e retenção) ${ }^{10,65,66}$.

Com base nestes conhecimentos, a HPMA tem sido utilizada como transportadora de agentes quimioterápicos (Figura 16) ${ }^{67-69}$. Como exemplo, será citado um modelo de PDEPT que usa um HPMA-copolímero-metacriloil-glicina-glicina-cefalosporinadoxorrubicina (HPMA-co-MA-GG-C-Dox) ${ }^{66}$, como pró-fármaco macromolecular e um HPMA-co-MA-GG- $\beta$-L como componente ativador deste pró-fármaco. HPMA-co-MA-GG-C-Dox tem massa molar de aproximadamente $31600 \mathrm{~g} / \mathrm{mol}$, sendo que 5,85\% deste valor corresponde à cefalosporina ligada à doxorrubicina. Já a $\beta$ lactamase livre $(\beta-\mathrm{L})$ tem massa molecular de $45 \mathrm{kDa}$, enquanto que o HPMA-co-MA-GG- $\beta$-L tem massa molar entre $75-150 \mathrm{kDa}^{66}$.

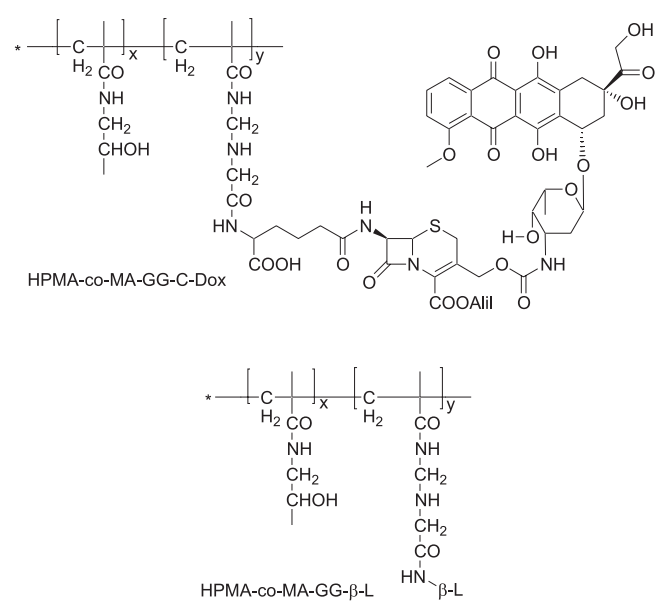

Figura 16. Estruturas de HPMA-co-MA-GG-C-Dox e HPMA-co-MA-GG- $\beta-L$

O HPMA-co-MA-GG- $\beta$-L reteve 70 e $80 \%$ de sua atividade, respectivamente, contra os substratos cefalosporina $\mathrm{C}$ e HPMA-coMA-GG-C-Dox. In vivo, HPMA-co-MA-GG- $\beta$-L marcado com ${ }^{125} \mathrm{I}$ exibiu prolongada concentração plasmática e grande concentração em tumores, comparado à $\beta$-lactamase livre, devido ao efeito $\mathrm{EPR}^{66}$.

Verificou-se, ainda, que a administração $i v$ de HPMA-co-MA-GGC-Dox em modelo xenográfico de melanoma B16F10, em ratos, seguida da administração de HPMA-co-MA-GG- $\beta$-L, após 5 h, le- 
vou à liberação de doxorrubicina livre e proporcionou significativo decréscimo no crescimento do tumor. Entretanto, tal atividade não foi observada quando foi utilizada doxorrubicina livre ou apenas HPMA-co-MA-GG-C-Dox ${ }^{66}$.

Este sistema PDEPT não exibiu nenhuma toxicidade na dose utilizada, e a determinação da dose máxima encontra-se em estu$\mathrm{do}^{66}$.

\section{GDEPT - “GENE-DIRECTED ENZYME-PRODRUG THERAPY”, VDEPT - "VIRUS-DIRECTED ENZYME- PRODRUG THERAPY” E GPAT - “GENETIC PRODRUG ACTIVATION THERAPY"}

GDEPT é uma estratégia que envolve transferência de um gene carregado, geralmente, por lipossomas às células tumorais, capaz de codificar a transcrição de uma enzima, que será responsável pela transformação de um pró-fármaco não tóxico em fármaco ativo, com a finalidade de promover a morte destas células ${ }^{15,21,70-72}$. Quando esta terapia gênica é farmacologicamente orientada por um vetor viral, que tem como função a distribuição do gene capaz de codificar a transcrição de uma enzima ativadora de pró-fármaco, é denominada VDEPT. Muitos vírus têm sido utilizados como vetores, incluindo retrovírus, adenovírus e vírus de Herpes simplex ${ }^{73}$.

GPAT é uma variação do GDEPT, que utiliza diferenças conhecidas entre células normais e tumorais para aumentar a seletividade ${ }^{74}$. Esta técnica envolve a criação de um gene artificial composto de uma seqüência regulatória transcricional tecido-específica (TRS), anexada a uma seqüência do gene da enzima que promove a ativação do pró-fármaco. O TRS consiste em um simples promotor, o qual pode ser ativado em tecidos específicos e, ainda, pode aumentar a taxa de expressão do gene desta enzima.

Os promotores ou TRSs são seqüências transcricionais diferentes de sequiências de células normais que dão expressão seletiva às células tumorais ${ }^{15,75}$. Para promover seletividade aos tumores nos sistemas GDEPT/VDEPT, é desejável ter a expressão da enzima regulada por um TRS.

Vários exemplos estão descritos na literatura. A Glaxo Welcome publicou uma patente utilizando TRSCEA (sequiência transcricional que confere seletividade para células que possuem antígeno carcinoma embriogênico) para regular a expressão de genes de enzimas ativadoras de pró-fármacos ${ }^{76}$. Este antígeno é expresso na maioria dos tumores sólidos, incluindo cólon, pulmão, estômago e pâncreas.

O uso de TRSCEA poderá, então, permitir a expressão seletiva de enzimas ativadoras de pró-fármacos na maioria dos tumores sólidos. Testes in vivo demonstraram que o uso de um sistema VDEPT, composto pelo promotor CEA (antígeno carcinoma embriogênico), de um adenovírus modificado como vetor e de um gene VHS-TQ (timidina quinase de vírus de Herpes simplex), capaz de codificar a enzima timidina quinase, que ativa o ganciclovir, revelou atenuação de metástases de fígado utilizando modelo xenográfico, em ratos $\mathrm{CB} 17 \mathrm{SCID}^{77}$.

A transcrição do gene MUC1(que codifica precursor de mucina 1) resulta no produto mucina epitelial polimórfica, que se encontra em grande quantidade, sendo altamente glicosilada, em muitos carcinomas em relação às células normais. $\mathrm{O}$ nível do produto do gene erbB2 (membro da família de genes do receptor do fator de crescimento epidermal) também é alto em neoplasias de mama e pâncre$\mathrm{as}^{78}$. Os TRS de MUC1 e erbB2 foram incorporados à sequiência transcricional responsável pela transcrição da enzima timidina quinase.

Todas essas sequiências foram introduzidas um vetor de retrovírus modificado. Foi verificado que a utilização conjunta dos dois promotores fez aumentar a expressão do gene da enzima, em células que expressam esses dois genes ${ }^{78}$ (Figura 17).

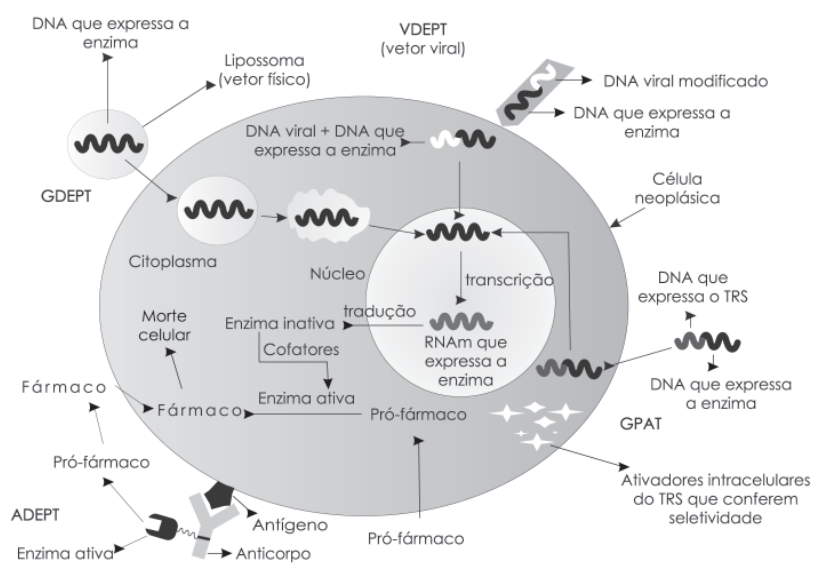

Figura 17. Representação esquemática dos sistemas que utilizam enzimas ativadoras de pró-fármaco

Promotores, baseados em elementos que respondem à hipóxia, estão sendo desenvolvidos para aumentar a seletividade em tumores de regiões de hipóxia, pois estes tumores são resistentes a quimioterápicos, devido à pobre perfusão que limita a disseminação de fármacos ${ }^{79-81}$.

No primeiro sistema GDEPT descrito foi utilizado um gene (VHSTQ) proveniente do vírus de Herpes simplex, que codifica a transcrição da enzima timidina quinase (VHS-TQ). Esta enzima viral é responsável pela monofosforilação de uma variedade de pró-fármacos baseados em guanosina, como ganciclovir ${ }^{82-84}$. Somente após a monofosforilação viral, é que as enzimas mamíferas endógenas são capazes de converter o pró-fármaco em uma forma ativa trifosforilada, um metabólito que provoca morte celular, por inibição da incorporação no DNA do nucleotídeo desoxiguanosina trifosfato, interrompendo a síntese do DNA durante a fase $\mathrm{S}^{85}$ (Figura 18).
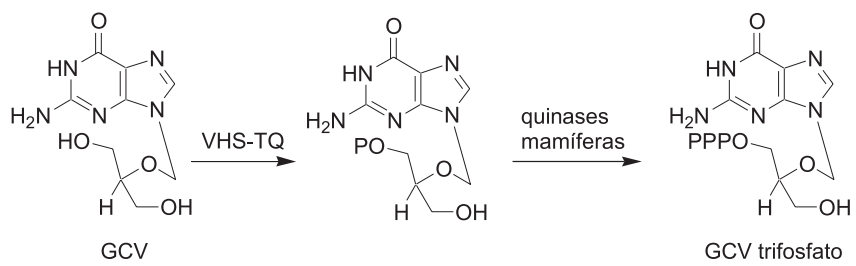

Figura 18. Conversão do ganciclovir em ganciclovir trifosfato pelas enzimas VHS-TQ e quinases mamíferas

As principais pesquisas envolvendo o ganciclovir em VDEPT estão relacionadas ao tratamento de glioblastoma. Em 248 pacientes cuja doença foi diagnosticada precocemente e que não receberam tratamento prévio, o vetor viral foi administrado por injeção intratumoral e, em seguida, o pró-fármaco foi administrado sistemicamente ${ }^{86}$.

Infelizmente, esta e outras pesquisas clínicas diferentemente de estudos iniciais em modelos animais não resultaram em benefícios, tanto no tempo de progressão tumoral, quanto no tempo de sobrevida dos pacientes, quando comparadas com terapias convencionais (radioterapia e remoção cirúrgica) ${ }^{86,87}$. Esses resultados são atribuídos à baixa taxa de liberação do gene VHS-TQ e, possivelmente, devido à dificuldade do fármaco atravessar a barreira hematoencefálica e as membranas de células tumorais.

Combinações desta terapia com outras vêm sendo exploradas. Algumas, com a finalidade de aumentar a liberação do gene utilizando proteases como tripsina ${ }^{88}$, outras usam radioterapia para aumentar a expressão do gene e a citotoxicidade do fármaco ${ }^{89,90}$.

Depois do gene VHS-TQ, o gene que codifica a transcrição da enzima citosina deaminase $(\mathrm{CD})$ é o mais utilizado para GDEPT $^{91}$. 
Esta enzima encontrada em uma variedade de bactérias e fungos tem como função a desaminação da citosina, transformando-a em uracila. Ela também promove a desaminação da flucitosina (5-FC), convertendo-a em fluoruracila (5-FU) (Figura 15), um fármaco citotóxico antineoplásico. As células mamíferas não produzem esta enzima, o que faz com que a 5-FC seja relativamente não tóxica ${ }^{92,93}$.

O fármaco 5-FC possui uma biodisponibilidade adequada, o que facilita sua penetração em células adjacentes não expressantes e aumenta sua capacidade de matar essas células, o que talvez explique que em tumores sólidos, in vitro, quando apenas $4 \%$ das células tumorais expressam o gene que codifica a enzima $\mathrm{CD}$, se pode observar $60 \%$ de regressão tumoral ${ }^{94}$.

O uso do promotor, antígeno carcinoembriônico (CEA), antígeno presente em tumores de câncer de cólon possibilita uma expressão maior e seletiva deste gene ${ }^{95}$. Modelos xenográficos de carcinoma de mama MDA-MB-231 e glioma humano induzidos em ratos foram controlados por uma dose intratumoral de um adenovírus que possui um gene que codifica a enzima $\mathrm{CD}$, seguida da administração sistêmica de 5-FC ${ }^{96,97}$.

Estudos similares têm demonstrado a eficácia do sistema CD/5FC em metástase hepática de carcinoma de cólon ${ }^{98}$ e de câncer de próstata ${ }^{99}$. Células de glioma 9L que coexpressam as duas enzimas, a enzima CD e a enzima uracil fosforibosiltransferase, as quais estão ausentes em células mamíferas, são 375 vezes mais sensíveis ao tratamento com 5 -FC que células que expressam somente a enzima $\mathrm{CD}^{100}$. Estudos in vivo, em modelo xenográfico de câncer de cólon induzido em ratos, utilizando a mesma fusão desses dois genes, demonstraram significante redução tumoral quando comparado com ratos não tratados ${ }^{101}$.

O sucesso desta estratégia é demonstrado pela pesquisa clínica, fase I, em pacientes com câncer de mama, que utilizaram o gene que codifica a enzima $\mathrm{CD}$ associado ao gene de um promotor tumor específico erbB-2 , exibindo $90 \%$ de expressão do gene que codifica a enzima $\mathrm{CD}$, nos casos em que as células tumorais eram erbB-2 positivas ${ }^{75}$.

O sistema GDEPT tem sido utilizado para aumentar o nível de $\beta$-glicuronidase em tumores. Neste sistema, o gene que codifica a enzima $\beta$-glucuronidase é usado para transmitir a ordem para as células tumorais secretarem esta enzima. Logo após, o pró-fármaco glucuronizado baseado em doxirrubicina (DOX-GA3 ou HMR1826) é administrado ${ }^{12,102,103}$ (Figura 19).
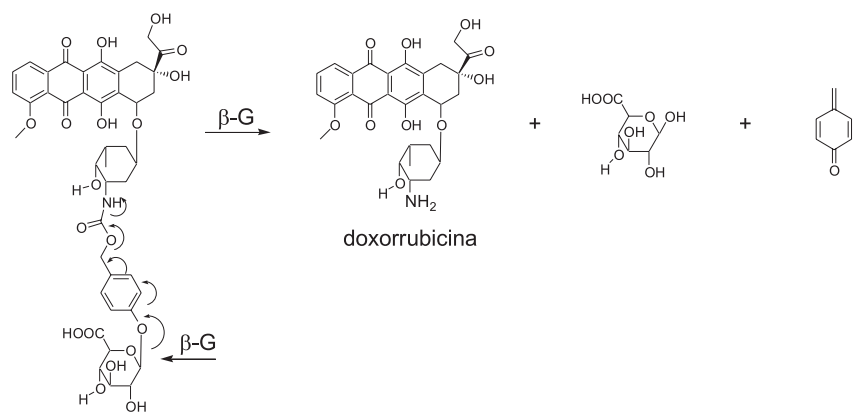

Figura 19. Conversão do pró-fármaco HMR1826 em doxorrubicina pela $\beta-G$

Tem sido demonstrado, in vitro, que a superexpressão deste gene resulta na presença da enzima aderida na superfície das células tumorais ${ }^{102}$, ao invés do seu confinamento em lisossomos ${ }^{104}$. Isto ocorre, provavelmente, devido à saturação do sistema receptor M6P (manose 6-fosfato).

Um estudo recente tem sido desenvolvido, utilizando uma linhagem de células cancerígenas humanas que expressam o gene que codifica esta enzima. Esta linhagem de células foi implantada subcutaneamente, usando um modelo xenográfico. Foi observada a regressão no volume do tumor, quando apenas $7 \%$ das células tumorais expressaram a $\beta$-glucuronidase ${ }^{12}$.

A enzima bacteriana nitrorredutase (NTR) converte o prófármaco CB1954 (Figura 20), em um potente agente alquilante ${ }^{105}$. Como não há homólogas da NTR endógenas capazes de promover a ativação deste pró-fármaco, um sistema VDEPT utilizando NTR/ CB1954 foi viável. Testes in vivo, que avaliaram a eficácia e segurança na administração de uma única injeção intratumoral de um vetor de adenovírus modificado (CTL102) expressante da NTR proveniente de $E$. coli, em doses que variam de $7,5 \times 10^{9}$ a $2 \times 10^{10}$ partículas virais, combinada com a administração sistêmica posterior do pró-fármaco CB1954, produziram efeitos antitumorais típicos em modelos xenográficos subcutâneos em quatro tipos de câncer ${ }^{106}$.

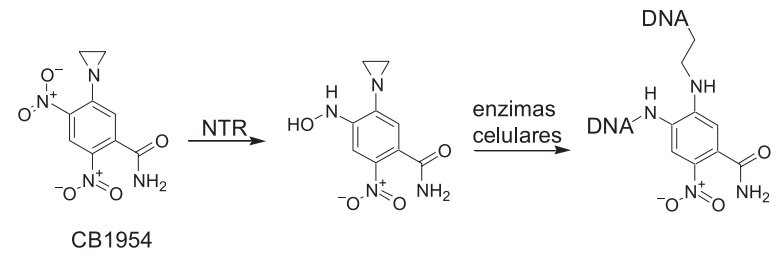

Figura 20. Ativação de CB1954 pela enzima nitrorredutase (NTR)

Uma triagem clínica em fase I foi efetuada para determinar a dose máxima de Ad-NTR (adenovírus modificado que expressa a enzima nitrorredutase) em pacientes com câncer de cólon com metástase hepática e em pacientes com hepatoma ${ }^{107-109}$. A toxicidade foi mínima e a enzima foi detectada nos tumores que foram retirados. A expressão do gene que codifica esta enzima aumentou com a elevação da dose administrada de Ad-NTR. O próximo ensaio clínico será realizado com a combinação do Ad-NTR na dose de $10^{11}$ partículas, com subseqüente administração de CB1954 ${ }^{108}$.

A carboxipeptidase G2 (CPG2), proveniente da bactéria Pseudomonas putida, cliva a porção glutamato de pró-fármacos tornando-os ativos ${ }^{109}$. Um gene modificado que codifica uma CPG2 mutante que, ao invés de se expressar intracelularmente, se expressa superficialmente vem sendo estudado ${ }^{111}$.

Excelentes resultados comparativos em linhagens de células cancerígenas WiDr, SR-OV-3 e A2780 demonstraram que a enzima mutante, em relação à não mutante, mostrou ser superior na ativação do pró-fármaco CMDA ${ }^{111}$ (Figura 21).

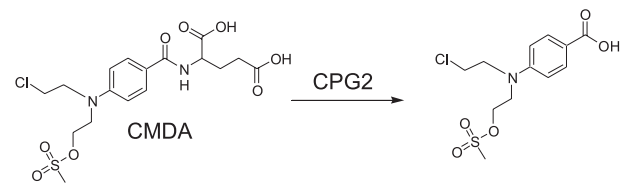

Figura 21. Ativação do CMDA pela CPG2

Baixos níveis da enzima modificada e uma baixa exposição do prófármaco foram necessários para matar células expressantes. Tumores xenográficos de carcinoma de mama MDA-MB-361 e outros tumores xenográficos, que expressam estavelmente a enzima mutante, têm sido desenvolvidos para análises, in vivo, em sistema GDEPT ${ }^{12-114}$.

Uma dose adequada do pró-fármaco CMDA causou um decréscimo no volume de tumores xenográficos e, em alguns casos, houve regressão total. Tumores que regrediram depois de um tratamento inicial, responderam quando foram novamente submetidos a um novo tratamento, indicando que o gene é estável e ativo por longo tempo. Em grupos onde a enzima mutante foi expressa, a administração de vários pró-fármacos resultou em regressão e/ou cura de tumores humanos xenográficos MDA-MB-361 e, também, de outros tumores xenogáficos ${ }^{112-114}$. 
O maior efeito foi observado em tumores onde $100 \%$ das células expressavam CPG2 mutante, com $67 \%$ de cura e, sobretudo, inibição de crescimento em 90 dias. Em alguns casos em que de 10 a $50 \%$ das células tumorais expressaram a CPG2 modificada, pode-se observar, cura efetiva, com $100 \%$ de células mortas. Quando tumores foram preparados com um inóculo contendo somente $10 \%$ de CPG2 mutante expressa, mais de $90 \%$ das células sofreram apoptose, enquanto em controles menos que $1 \%$ das células morreram ${ }^{113}$.

\section{CONCLUSÃO}

Devido à baixa vascularização em tumores, a atividade de imunoconjugados volumosos quimicamente ligados é restrita, não sendo possível a distribuição em todas as células tumorais. Além disso, a ligação do conjugado à superfície celular é limitada pela heterogenicidade do antígeno. Outros problemas do sistema ADEPT incluem custos e dificuldade com o desenvolvimento e a purificação de anticorpos, mas o principal problema é a imunogenicidade do imunoconjugado, o que limita ciclos múltiplos de sua aplicação. Para resolver este problema muitas propostas têm sido apresentadas, incluindo o uso de proteínas humanizadas e a administração concomitante de imunossupressores. As recentes pesquisas clínicas da primeira geração do sistema ADEPT não mostraram os resultados desejados, mas encorajaram o desenvolvimento da segunda geração. A segunda geração do sistema ADEPT incorpora, além de pró-fármacos melhorados, o uso da tecnologia de DNA recombinante, para obter proteínas fundidas ao invés de conjugados químicos, oferecendo grande chance de sucesso clínico, pois estas proteínas retêm alta especificidade, menor imunogenicidade e são menos volumosas.

A maior vantagem dos sistemas GDEPT/VDEPT/GPAT sobre o ADEPT é a potencial versatilidade em encontrar seletividade. Nestes sistemas, genes que codificam enzimas podem ser especificamente distribuídos através de TRS, que direciona a expressão da enzima para células alvo. No entanto, existem alguns riscos teóricos, incluindo mutagênese, formação de anticorpos anti-DNA, infecção local e ulceração de nódulo tumoral, restringindo seus usos. No caso do sistema VDEPT, a maioria dos vetores viral é construída para possuírem replicação deficiente, contudo, há risco, mesmo que pequeno, de reversão do vírus para sua forma selvagem. Outra desvantagem associada a vetores retrovirais é que suas células alvo são somente as que estão em divisão e mesmo em um nódulo tumoral em crescimento, apenas de 6 a $20 \%$ das células estão em fase $\mathrm{S}$ se proliferando. No entanto, este inconveniente pode ser uma vantagem para tumores cerebrais, onde somente células tumorais estão se multiplicando. Comparado com retrovírus, o adenovírus tem algumas vantagens, incluindo a capacidade de se proliferar tanto em células que estão se dividindo, como nas que não estão, mas apresenta curtos períodos de expressão do gene nas células em divisão.

O maior problema limitante da aplicação clínica destes sistemas (GDEPT/VDEPT/GPAT) é o desenvolvimento de uma forma sistêmica para distribuição do gene, apesar de que injeções intratumorais vêm mostrando resultados encorajadores. Estas injeções podem resultar em atividade em locais distantes do local da aplicação, o que pode ser um fator positivo para tratamento de metástases, embora seja necessário utilizar um veículo de distribuição de gene sistêmico.

Com base nestas variáveis, a escolha por GDEPT/VDEPT/GPAT ou ADEPT é dependente do cenário clínico e dos riscos e limitações associados a cada sistema. Na terapêutica de doenças altamente invasivas em que se utilizam fármacos extremamente tóxicos, como o câncer, estes sistemas se constituem esperança na distribuição destes fármacos em células neoplásicas com alta seletividade diminuindo, desta forma, a toxicidade destes e, conse- qüentemente, ocasionando menor sofrimento ao paciente. Os estudos ainda são iniciais, mas merecedores de serem explorados como alternativas ao tratamento convencional.

\section{AGRADECIMENTOS}

À FAPESP (Proc. no 03/04595-7, 03/05791-4, Proc. 01/01192-3) e ao PADC/FCF - UNESP Proc. 2003/14-1 pelos auxílios concedidos.

\section{GLOSSÁRIO DE TERMOS TÉCNICOS}

A2780: linhagem de células de adenocarcinoma humano

A33: antígeno de carcinoma de cólon

A549: linhagem de células de câncer de pulmão

ADEPT ("antibody-directed enzyme prodrug therapy"): terapia que utiliza anticorpo acoplado a uma enzima ativadora de prófármacos

Ad-NTR: adenovírus modificado que expressa a enzima nitrorredutase

C28: anticorpo que se liga às células epiteliais

Capan 2: linhagem de células de câncer de pâncreas

CB17SCID: rato com imunodeficiência grave

$\mathrm{CD}$ : citosina deaminase

CEA: antígeno carcinoma embriogênico

CHO: ovário de hamster chinês

C-Mel: cefalosporina-melfalano

CMDA: ácido 4-[(2-cloroetil)(2-mesiloxetil)amino]benzoil-Lglutâmico

COLO 205: linhagem de células de câncer de cólon

CPG2: carboxipeptidase G2

EPR: aumento da permeabilidade e retenção

ErbB2: membro da família de genes do receptor do fator de crescimento epidermal

5-FC: flucitosina

5-FU: fluoruracila

$\beta$-G: $\beta$-glicuronidase

GCV: ganciclovir

GDEPT ("gene-directed enzyme prodrug therapy"): terapia que utiliza gene que expressa a enzima ativadora de pró-fármacos

GPAT ("genetic prodrug activation therapy"): terapia que utiliza a ativação genética de pró-fármacos

HPMA: $n$-(2-hidroxipropil)-metacrilamida

HPMA-co-MA-GG-C-Dox: HPMA-copolímero-metacriloil-glicinaglicina-cefalosporina-doxorrubicina

HPMA-co-MA-GG- $\beta$-L: HPMA-copolímero-metacriloil-glicinaglicina- $\beta$-lactamase

IgG: imunoglobulina $\mathrm{G}$

K562: linhagem de células de leucemia humana

$\beta$-L: $\beta$-lactamase

L49-sFvbL: proteína fundida recombinante composta de uma cadeia simples de fragmento variável derivada de anticorpo monoclonal L49 e da enzima $\beta$-L

LS174T: linhagem de células de tumor de cólon humano

M6P: manose 6-fosfato

mAc: anticorpo monoclonal

mAc-CD: anticorpo monoclonal acoplado à enzima citosina deaminase

mAc-CPG2: anticorpo monoclonal acoplado à enzima carboxipeptidase $\mathrm{G} 2$

MCF7: linhagem de células de carcinoma de mama

MDA-MB-361: linhagem de células de carcinoma de mama

MiaPaCa2: linhagem de células de câncer de pâncreas

MTX: metotrexato

MUC1: precursor de mucina 1 
NTR: nitrorredutase

OVCAR-3: linhagem de células de tumor de ovário humano

PDEPT ("polymer directed enzyme prodrug therapy"): terapia que utiliza polímero acoplado a uma enzima ativadora de pró-fármacos

SB 43: anticorpo galactosilado anti-mAc-CPG2

scFvc28: fragmento variável de cadeia simples do anticorpo humano $\mathrm{C} 28$

scFvC28- $\beta$-G: fragmento variável de cadeia simples do anticorpo humano $\mathrm{C} 28$ acoplado à enzima beta-glicuronidase

SR-OV-3: linhagem de células de adenocarcinoma humano

TRS: seqüência regulatória transcricional tecido específica

TRSCEA: sequiência regulatória transcricional do antígeno carcinoma embriogênico

VDEPT ("vírus-directed enzyme prodrug therapy"): terapia que utiliza vírus que expressa enzima ativadora de pró-fármacos

VH: fragmento variável de cadeia pesada do anticorpo

VHS-TQ: timidina quinase de vírus de Herpes simplex

VL: fragmento variável de cadeia leve do anticorpo

WiDr: linhagem de células de carcinoma de cólon humano

\section{REFERÊNCIAS}

1. Tsalic, M.; Bar, S. G.; Beny, A.; Visel, B.; Haim, N.; Am. J. Clin. Oncol. 2003, 26, 103.

2. Extermann, M.; Chen, H.; Cantor, A. B.; Corcoran, M. B.; Meyer, J.; Grendys, E.; Cavanaugh, D.; Antonek, S.; Camarata, A.; Haley, W. E.; Balducci, L.; Eur. J. Cancer. 2002, 38, 1466.

3. Ma, B.; Yeo, W.; Hui, P.; Wo, W. M.; Jonson, P. J.; Radiother.Oncol. 2002, $62,185$.

4. Edmonson, J. H.; Petersen, I. A.; Shives, T. C.; Mahoney, M. R.; Rock, M. G.; Haddock, M. G.; Sim, F. H.; Maples, W. J.; O'connor, M. I.; Gunderson, L. L.; Foo, M. L.; Pritchard, D. J.; Buckner, J. C.; Stafford, S.; Cancer 2002, 94, 786.

5. Blagosklonny, M. V.; Leukemia 1999, 13, 2031.

6. Pusztai, L.; Siddik, Z. H.; Mills, G. B.; Bast, R. C. J.; Acta Oncol. Stockholm. 1998, 37, 629.

7. Krishna R.; Mayer D. L.; Cancer Res. 1997, 57, 5246.

8. Fracasso, P. M.; Westerveldt, P.; Fears, C. A.; Rosen, D. M.; Zuhowski, E. G.; Cazenave, L. A.; Litchman, M.; Egorin, M. J.; J. Clin. Oncol. 2000, $18,1124$.

9. Bundgaard, H.; Drugs Fut. 1991, 16, 443.

10. Chung, M. C.; Ferreira, E. I.; Quim. Nova 1999, $22,75$.

11. Weyel, D.; Sedlacek, H. H.; Muller, R.; Brusselbach, S.; Gene Ther. 2000, 7, 224.

12. Hamstra, D. A.; Rehemtulla, A.; Hum. Gene Ther. 1999, 10, 235.

13. Xu, G.; Mcleod, H. L.; Clin. Cancer Res. 2001, 7, 3314.

14. Jungheim, L. N.; Sherpherd, T. A.; Chem. Rev. 1994, 94, 1553.

15. Niculescu-Duvaz, I.; Spooner, R.; Marais, R.; Springer, C. J.; Bioconjugate Chem. 1998, 9, 4 .

16. Springer, C. J.; Antoniw, P.; Bagshawe, K. D.; Wilman, D. E. V.; Anticancer Drug Des. 1991, 6, 467.

17. Rainov, N. G.; Dobberstein, K. U.; Sena-Esteves, M.; Herrlinger, U.; Kramm, C. M.; Philpot, R. M.; Hilton, J.; Chiocca, E. A.; Breakefield, X. O.; Hum. Gene Ther. 1998, 9, 1261.

18. Syrigos, K. N.; Epenetos, A. A.; Anticancer Res. 1999, 19, 605.

19. Dimaggio, J. J.; Scheinberg, D. A.; Houghton, A. N.; Cancer Chemother. Biol. Response Modif. Annual 11. 1990, 177.

20. Vitetta, E. S.; Fulton, R. J.; May, R. D.; Till, M.; Uhr, J. M.; Science 1987, 238,1098

21. Nenny, W. A.; Wilson, W. R.; J. Pharm. Pharmacol. 1998, 50, 387.

22. Martin, J.; Stribbling, S. M.; Poom, G. K.; Begent, R. H. J.; Napier, M.; Sharma, S. K.; Springer, C.; J. Cancer Chemother. Pharmacol. 1997, 40, 189.

23. Napier, M. P.; Sharma, S. K.; Springer, C. J.; Bagshawe, K. D.; Green, A. J.; Martin, J.; Stribbling, S. M.; Cushen. N.; O'maley, D.; Begent, R. H. J.; Clin. Cancer Res. 2000, 6, 765.

24. Haisma, H. J.; Sernee, M. F.; Hooijberg, E.; Brakenhoff, R. H.; van der Meulen-Muileman, I. H.; Pinedo, H. M.; Boven, E.; Blood 1998, 92, 184.

25. Pedley, R. B.; Sharma, S. K.; Boxer, G. M.; Boden, R.; Stribbling, S. M.; Davies, L.; Springer, C. J.; Begent, R. H. J.; Cancer Res. 1999, 59, 3998.

26. Wolfe, L. A.; Mullin, R. J.; Laethem, R.; Blumenkopf, T. A.; Cory, M.; Miller, J. P.; Keith, B. R.; Humphreys, J.; Smith, G. K.; Bioconjugate Chem. 1999, 10,38 .
27. Bosslet, K.; Czech, J.; Lorens, P.; Sedlacek, H. H.; Schuermann, M.; Seeman, G.; Br. J. Cancer 1992, 65, 234.

28. Vrudhula, V. M.; Svensson, H. P.; Kennedy, K. A.; Senter, P. N.; Wallace, P. M.; Bioconjugate Chem. 1993, 4, 334.

29. Svensson, H. P.; Wallace, P. M.; Senter, P. D.; Bioconjugate Chem. 1994, $5,262$.

30. Jung, M.; Mini Rev. Med. Chem. 2001, 1, 399.

31. Sahin, U.; Hartmann, F.; Senter, P.; Pohl, C.; Engert, A.; Diehl, V.; Pfreundschuh, M.; Cancer Res. 1990, 50, 6944.

32. Goshorn, S. C.; Svensson, H. P.; Kerr, B. E.; Somerville, J. E.; Senter, P. D.; Fell, H. P.; Cancer Res. 1993, 53, 2123.

33. Michael, N. P.; Chester, K. A.; Melton, R. G.; Robson, L.; Nicholas, W.; Boden, J. A.; Pedley, R. B.; Begente, R. H. J.; Sherwood, F. R.; Minton, P. $\mathrm{N}$.; Immunotechnology 1996, 2, 47.

34. Bhatia, J.; Sharma, S. K.; Chester, K. A.; Pedley, R. B.; Boden, R. W.; Read, D. A.; Boxer, G. M.; Michael, N. P.; Begent, R. H.; Int. J. Cancer 2000, 85,571 .

35. Kerr, D. E.; Vrudhula, V. M.; Svensson, H. P.; Siemers, N. O.; Senter, P. D.; Bioconjugate Chem. 1999, 10, 1084.

36. De Graaf, M.; Boven, E.; Scheeren, H. W.; Haisma, H. J.; Pinedo, H. M.; Curr. Pharm. Des. 2002, 8, 1391.

37. Roffler, S. F.; Wang, S. M.; Chern, J. W.; Yeh, M. J.; Tung, E.; Biomed. Pharmacol. 1991, 42, 2062.

38. Wang, S. M.; Chern, J. W.; Yeh, M. Y.; Ng, J. C.; Tung, E.; Hoffler, S. F.; Cancer Res. 1992, 52, 4484.

39. Bakina, E.; Wu, Z.; Rosenblum, M.; Farquhar, D.; J. Med. Chem. 1997, 40, 4013.

40. Haisma, H. J.; Boven, E.; van Muijen, M.; De Jong, J.; van der Vijgh, W. J. F.; Pinedo, H. M. A.; Br. J. Cancer 1992, 66, 474.

41. Haisma, van Muijen, M.; Pinedo, H. M.; Boven, E.; Cell. Biophys. 1994, 24/25, 185.

42. De Graaf, M.; Boven, E.; Oosterhoff, D.; van der Meule-Muileman, I. H.; Huls, G. A.; Gerritsen, W. R.; Haisma, H. J.; Pinedo, H. N.; Br. J. Cancer 2002, 86,811

43. Springer, C. J.; Antoniw, P.; Bagshawe, K. D.; Searle, F.; Bisset, G. M.; Jarman, M.; J. Med. Chem. 1990, 33, 677.

44. Springer, C. J.; Bagshawe, K. D.; Sharma, S. K.; Searle, F.; Boden, J. A.; Antoniw, P.; Burke, P. J.; Rogers, G. T.; Sherwood, R. F.; Melton, R. G.; Eur. J. Cancer 1991, 27, 1361.

45. Bagshawe, K. D.; Br. J. Cancer 1989, 60, 275.

46. Bagshawe, K. D.; Sharma, S. K.; Springer, C. J.; Antoniw, P.; Rogers, G. T.; Burke, P. J.; Melton, R.; Sherwood, R.; Antibody Immunoconj. Radiopharm. 1991, 4, 915.

47. Bagshawe, K. D.; Adv. Pharmacol. 1993, 24, 99.

48. Sharma, S. K.; Bagshawe, K. D.; Melton, R. G.; Sherwood, R. F.; Cell. Biophys. 1992, 21, 109.

49. Spencer, D. I. R.; Robson, L.; Purdy, D.; Whitelegg, N. R.; Michael, N. P.; Bhatia, J.; Sharma, S. K.; Rees, A. R.; Minton, N. P.; Begent, R. H. J.; Chester, K. A.; Proteomics 2002, 2, 271.

50. Mayer, A.; Sharma, S. K.; Tolner, B.; Minton, N. P.; Purdy, D.; Amlot, P.; Tharankan, G.; Begent, R. H.; Chester, K. A.; Br. J. Cancer 2004, 90, 2402.

51. European Patent Application, 0382411 A2, 1990.

52. Jungheim, L. N.; Shepherd, T. A.; Meyer, D. L.; J. Org. Chem. 1992, 57, 2334.

53. Meyer, D. L.; Jungheim, L. N.; Mikolajczyk, S. D.; Shepherd, T. A.; Starling, J. J.; Ahlen, C. N.; Bioconjugate Chem. 1992, 3, 42.

54. Meyer, D. L.; Jungheim, L, N.; Law, K. L.; Mikolajczyk, S, D.; Shepherd, T. A.; Mackensen, D. G.; Starling, J. J.; Cancer Res. 1993, 53, 3956.

55. Veinberg, G.; Shestakova, I.; Vorona, M.; Kanape, I.; Domrachova, I.; Edmunds, L.; Bioorg. Med. Chem. Lett. 2004, 14, 1007.

56. Vrudhula, V. M.; Kerr, D. E.; Siemers, N. O.; Dubowchik, G. M.; Senter, P. D.; Bioorg. Med. Chem. Lett. 2003, 13, 539.

57. Hakimelahi, G. H.; Shia, K. S.; Pasdar, M.; Hakimelahi, S.; Khalafi, N. A.; Soltani, M. N.; Mei, N. W.; Mei, H. C.; Saboury, A. A.; Rezaei, T. N.; Moosavi, M. A. A.; Bioorg. Med. Chem. 2002, 10, 2927.

58. Hakimelahi, G. H.; Ly, T. W.; Yu, S. F.; Zakerinia, M.; Khalafi, M. A.; Soltani, M. N.; Gorgani, M. N.; Chadegani, A. R.; Moosavi, M. A. A.; Bioorg. Med. Chem. 2001, 9, 2139.

59. Mcdonagh, C.; Beam, K. S.; Wu, G. J. S.; Chen, J. H.; Chace, D. F.; Senter, P. D.; Francisco, J. A.; Bioconjugate Chem. 2003, 14, 860.

60. Cortez-Retamozo, V.; Backmann, N.; Senter, P. D.; Werney, U.; De Baetselier, P.; Muyldermans, S.; Revets, H.; Cancer Res. 2004, 64, 2853.

61. Stijilemans, B.; Conrath, K.; Cortez-Retamozo, V.; Van Xong, H.; Wyns, L.; Senter, P.; Revest, H.; De Baetselier, P.; Muyldermans, S.; Magez, S.; J. Biol. Chem. 2004, 279, 1256.

62. Senter, P. D.; Su, P. C. D.; Katsuragi, T.; Sakai, T.; Cosand, W. L.; Hellström, I.; Hellström, K. E.; Bioconjugate Chem. 1991, 2, 447. 
63. Deckert, P. M.; Renner, C.; Cohen, L. S.; Jungbluth, A.; Ritter, G.; Bertino, J. R.; Old, L. J.; Welt, S.; Br. J Cancer 2003, 88, 937.

64. Satchi, R.; Connors, T. A.; Duncan, R.; Br. J. Cancer 2001, 85, 1070

65. Maeda, H.; Wu, J.; Sawa, T.; Matsumura, Y.; Hori, K.; J. Controlled Release 2000, 65, 271.

66. Satchi-Fainaro, R.; Hailu, H.; Davies, J. W.; Summerford, C.; Duncan, R.; Bioconjugate Chem. 2003, 14, 797.

67. Satchi-Fainaro, R.; Puder, M.; Davies, J. W.; Tran, H. T.; Sampson, D. A.; Greene, A. K.; Corfas, G.; Folkman, J.; Eur. J. Cancer 2004, 40, 148.

68. Lin, X.; Zhang, Q.; Rice, J. R.; Stewart, D. R.; Nowotnik, D. P.; Howell, S. B.; Eur. J. Cancer 2004, 40, 291.

69. David, A.; Kopeckova, P.; Minko, T.; Rubinstein, A.; Kopecek, J.; Eur. J. Cancer 2004, 40, 148.

70. Friedlos, F.; Court, S.; Ford, M.; Denny, W. A.; Springer C.; Gene Ther. 1998, 5,105

71. Friedlos, F.; Denny, W. A.; Palmer, B. D.; Springer, C. J.; J. Med. Chem. 1997, 40, 1270 .

72. Clark, A. J.; Iwobi, M.; Cui, W.; Crompton, M.; Harold, G; Hobbs, S.; Kamalati, T.; Knox, P.; Neil, C.; Yull, F.; Gusterson, B.; Gene Ther. 1997, 4, 101.

73. Nakamura, H6; Mullen, J. T6; Chandrasekhar, S6; Pawlik, T. M6; Yoon, S. S6; Tanabe, K. K.; Cancer Res. 2001, 61, 5447.

74. Rigg, A.; Sikora, K.; Mol. Med. Today 1997, 3, 359.

75. Panhda, H.; Martin, L. A.; Rigg, A.; Hurst, H. C.; Stamp, G. W. H.; Sikora, K.; Lemoine, N. R.; J. Clin. Oncol. 1999, 17, 2180.

76. The Wellcome Foundation Ltd., Wo9514100 (1995).

77. Okabe, S.; Arai, T.; Yamashita, H.; Sugihara, K.; J. Cancer Res. Clin. Oncol. 2003, 129, 367

78. Ring, C. J. A.; Blouin, P.; Martin, L. A.; Hurst, H. C.; Lemoine, N. R.; Gene Ther. 1997, 4, 1045.

79. William, K. J.; Cowen, R. L. E.; Stratford, I. J.; Breast Cancer Res. 2001 , 3, 328.

80. Post, D. E.; van Meir, E. G.; Gene Ther. 2001, 8, 1801

81. Marples, B.; Greco, O.; Joiner, M. C.; Scott, S. D.; Eur. J. Cancer 2002, $38,231$.

82. De Clercq, E.; Nucleosides Nucleotides Nucleic Acids 2000, 19, 1531.

83. De Clercq, E.; Andrei, G.; Snoeck, R.; De Bolle, L.; Naesens, L.; Degreve, B.; Balzarini, J.; Zhang, Y.; Schols, D.; Leyssen, P.; Ying, C.; Neyts, J.; Nucleosides Nucleotides Nucleic Acids 2001, 20, 271.

84. Okada, T.; Caplen, N. J.; Ramsey, W. J.; Onodera, M.; Shimazaki, K.; Nomoto, T.; Ajalli, R.; Wildner, O.; Morris, J.; Kume, A.; Hamada, H.; Blaese, R. M.; Ozawa, K.; J. Gene. Med. 2004, 6, 288.

85. Moolten, F. L.; Cancer Res. 1986, 46, 5276.

86. Rainov, N. G.; Dobberstein, K. U.; Sena-Esteves, M.; Herrlinger, U.; Kramm, C. M.; Philpot, R. M.; Hilton, J.; Chiocca, E. A.; Breakefield, X. O.; Hum. Gene Ther. 2000, 11, 2389.

87. Fillat, C.; Carrio, M.; Cascante, A.; Sangro, B.; Curr. Gene. Ther. 2003, 3, 13.

88. Kuriyama, N.; Kuriyama, H.; Julin, C. M.; Lamborn, K. R.; Israel, M. A.; Cancer Res. 2001, 61, 1805.

89. Marples, B.; Greco, O.; Joiner, M. C.; Scott, S. D.; Eur. J. Cancer 2002, $38,231$.

90. Nishihara, E.; Nagayama, Y.; Mawatari, F.; Tanaka, K.; Namba, H.; Niwa, M.; Yamashita, S.; Endocrinology 1997, 138, 4577.
91. Dabrowska, A.; Szary, J.; Kowalczuk, M.; Szala, S.; Ugorski, M.; Acta Biochim. Pol. 2004, 51, 723.

92. Mcneish, I. A.; Green, N. K.; Gilligan, M. G.; Ford, M. J.; Mautner, V.; Young, L. S.; Kerr, D. J.; Gene Ther. 1998, 5, 1061

93. Mullen, C. A.; Kilstrup, M.; Blaese, R. M.; Proc. Natl. Acad. Sci. U.S.A. 1992, 89, 33

94. Trinh, Q. T.; Austin, E. A.; Murray, D. M.; Knick, V. C.; Huber, B. E.; Cancer Res. 1995, 55, 4808.

95. Nyati, M. K.; Sreekumar, A.; Li, S.; Zhang, M.; Rynkiewicz, S. D.; Chinnaiyan, A. M.; Rehemtulla, A.; Lawrence, T. S.; Cancer Res. 2002, $62,2337$.

96. Li, Z.; Shanmugam, N.; Katayose, D.; Huber. B.; Srivastava. S.; Cowan. K.; Seth. P.; Cancer Gene Ther. 1997, 4, 113.

97. Miller, C. R.; Williams, C. R.; Buchsbaum, D. J.; Gillespie, G. Y.; Cancer Res. 2002, 62, 773

98. Topf, N.; Worgall, S.; Hackett, N. R.; Crystal, R. G.; Gene Ther. 1998, 5, 507.

99. O’keefe, D. S.; Uchida, A.; Bacich, D. J.; Watt, F. B.; Martorana, A.; Molloy, P. L.; Heston, W. D.; Prostate 2000, 45, 149.

100. Adachi, Y.; Tamiya, T.; Ichikawa, T.; Terada, K.; Ono, Y.; Matsumoto, K.; Furuta, T.; Hamada, H.; Ohmoto, T.; Hum. Gene Ther. 2000, 11, 77.

101. Chung-Faye, G. A.; Chen, M. J.; Green, N. K.; Burton, A.; Anderson, D.; Mautner, V.; Searle, P. F.; Kerr, D. J.; Gene Ther. 2001, 8, 1547.

102. Fonseca, M. J.; Storm, G.; Hennink, W. E.; Gerritsen, W. R.; Haisma, H. J.; Gene Med. 1999, 1, 407.

103. Graaf, M.; Pinedo, H. M.; Oosterhoff, D.; van der Meulen-Muileman, I. H.; Gerritsen, W. R.; Haisma, H. J.; Boven, E.; Hum. Gene Ther. 2004, 15, 229.

104. Brot, F. E.; Bell, C. E. Jr.; Sly, W. S.; Biochemistry 1978, 17, 385.

105. Helsby, N. A.; Ferry, D. M.; Patterson, A. V.; Pullen, S. M.; Wilson, W. R.; Br. J. Cancer 2004, 90, 1084

106. Djeha, A. H.; Thomson, T. A.; Leung, H.; Searle, P. F.; Yong, L. S.; Kerr, D. J.; Harris, P. A.; Mountain, A.; Wrighton, C. J.; Mol. Ther. 2001, 3, 233.

107. Chung-Faye, G.; Palmer, D.; Anderson, D.; Clark, J.; Downes, M.; Baddeley, J.; Hussain, S.; Murray, P. I.; Searle, P.; Seymour, L.; Harris, P. A.; Ferry, D.; Kerr, D. J.; Clin Cancer Res. 2001, 7, 2662

108. Palmer, D. H.; Maltner, V.; Hull, D.; Ellis, J.; Moutain, A.; Searle, P.; Young, L. S.; Gerritsen, W.; James, N. D.; Kerr, D. J.; Proc. Am. Soc. Clin. Oncol. 2003, 22, 198

109. James, N. D.; Young, J. G.; Patel, P.; Leung, H.; Searle, P.; Mautner, V.; Ellis, J.; Doherty, A.; Wallace, M.; Young, L.; Proc. Am. Soc. Clin. Oncol. 2003, 22, 204.

110. Springer, C. J.; Antoniw, P.; Bagshawe, K. D.; Searle, F.; Bisset, G. M.; Jarman, M.; J. Med. Chem. 1990, 33, 677.

111. Spooner, R. A.; Martin, J.; Friedlos, F.; Marais, R.; Springer, C. J.; Cancer Gene Ther. 2000, 7, 1348

112. Stribbling, S. M.; Friedlos, F.; Martin, J.; Davies, L.; Spooner, R. A.; Marais, R.; Springer, C. J.; Hum. Gene Ther. 2000, 11, 285.

113. Friedlos. F.; Davies, L.; Scanlon, I.; Ogilvie, L. M.; Cancer Res. 2002, 62, 1724

114. Niculescu-Duvaz, D.; Niculescu-Duvas, I.; Friedlos, F.; Martin, J.; Lehouritis. P.; Springer, C. J.; J. Med. Chem. 2003, 46, 1690. 